
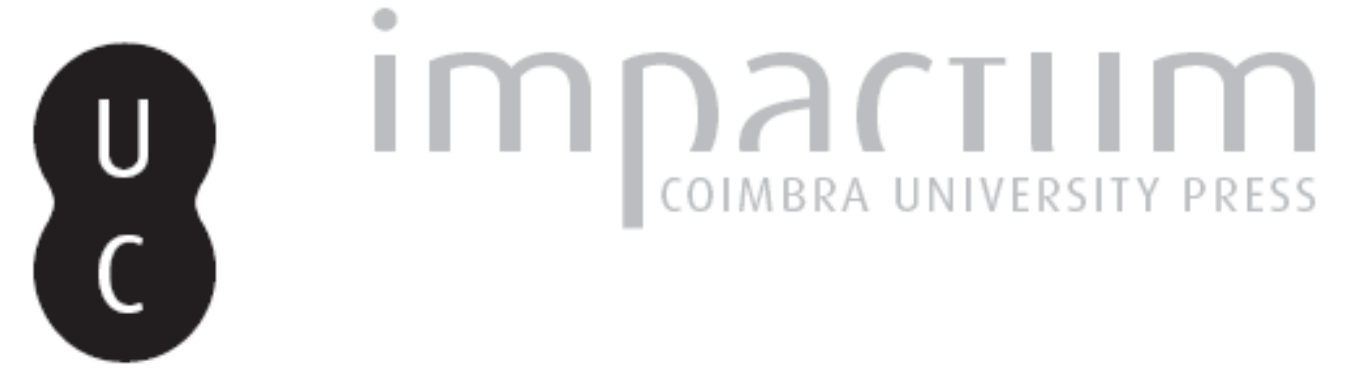

\title{
Os mapas em Portugal: passado, presente e futuro da Cartografia portuguesa segundo vários especialistas nacionais e estrangeiros
}

Autor(es): $\quad$ Rebelo, Fernando

Publicado por: Associação Portuguesa de Riscos, Prevenção e Segurança

URL persistente:

URI:http://hdl.handle.net/10316.2/40171

DOI:

DOI:https://doi.org/10.14195/1647-7723_3_8

Accessed : $\quad$ 26-Apr-2023 12:46:32

A navegação consulta e descarregamento dos títulos inseridos nas Bibliotecas Digitais UC Digitalis, UC Pombalina e UC Impactum, pressupõem a aceitação plena e sem reservas dos Termos e Condições de Uso destas Bibliotecas Digitais, disponíveis em https://digitalis.uc.pt/pt-pt/termos.

Conforme exposto nos referidos Termos e Condições de Uso, o descarregamento de títulos de acesso restrito requer uma licença válida de autorização devendo o utilizador aceder ao(s) documento(s) a partir de um endereço de IP da instituição detentora da supramencionada licença.

Ao utilizador é apenas permitido o descarregamento para uso pessoal, pelo que o emprego do(s) título(s) descarregado(s) para outro fim, designadamente comercial, carece de autorização do respetivo autor ou editor da obra.

Na medida em que todas as obras da UC Digitalis se encontram protegidas pelo Código do Direito de Autor e Direitos Conexos e demais legislação aplicável, toda a cópia, parcial ou total, deste documento, nos casos em que é legalmente admitida, deverá conter ou fazer-se acompanhar por este aviso.

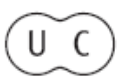




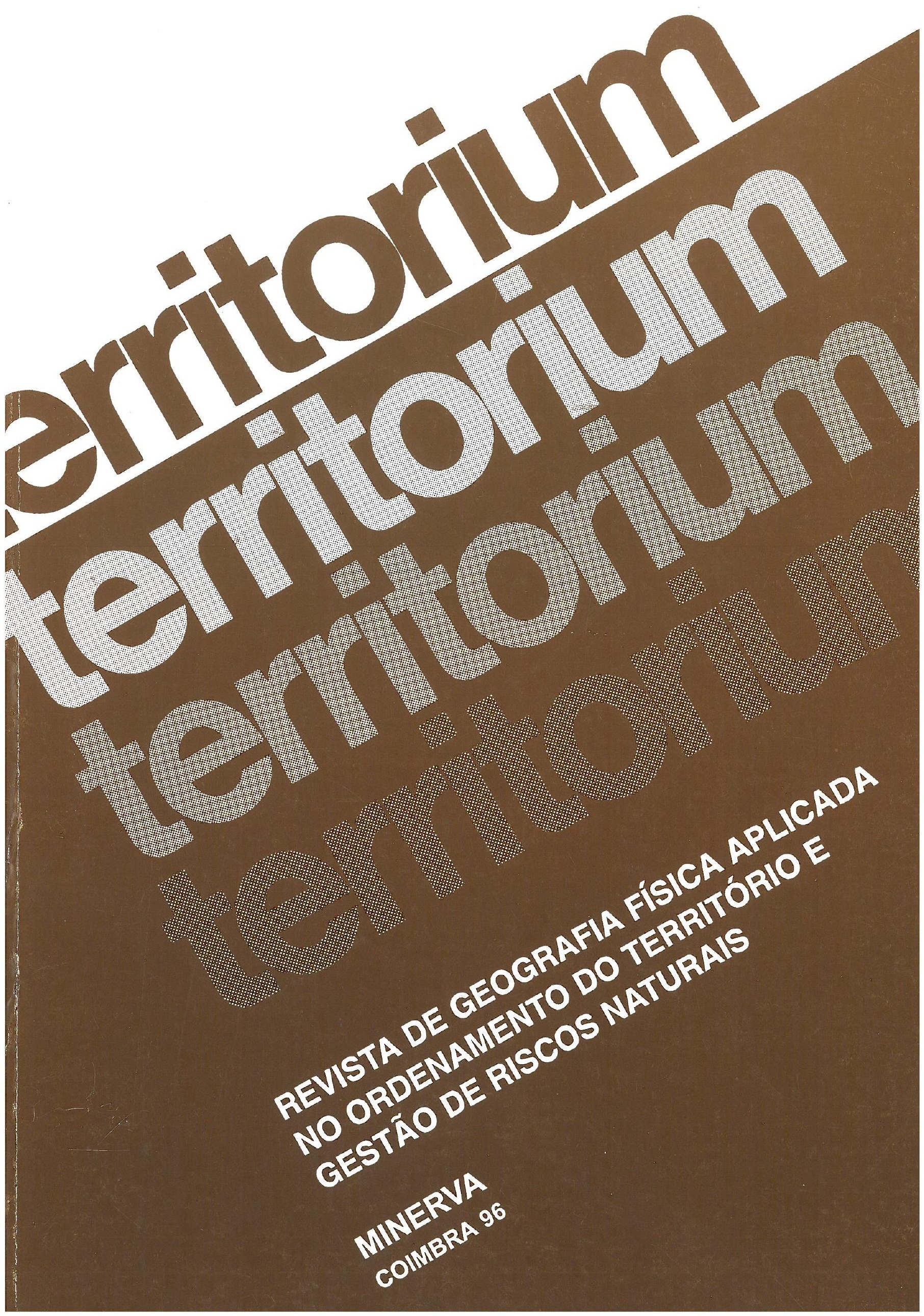




\section{Os mapas em Portugal. Passado, presente e futuro da Cartografia portuguesa segundo vários especialistas nacionais e estrangeiros}

\section{Fernando Rebelo}

Os mapas em Portugal. Da tradição aos novos rumos da cartografia (Lisboa, Cosmos, 1995, 344 p.) é um livro constituído por oito capítulos escritos por treze especialistas (geógrafos e engenheiros geógrafos), sob a coordenação de Maria Helena Dias.

A coordenadora inicia o trabalho com uma "Introdução", em que refere as características gerais dos diferentes capítulos. E foi precisamente numa frase aí incluída que nos inspirámos para o título desta recensão - "é do passado, do presente e do futuro da Cartografia portuguesa que se fala neste livro" (p. 18).

Segue-se a apresentação dos 13 autores através de uma curta resenha biográfica em que se salientam as relações de cada um com o tema em estudo, geralmente dedutíveis pelos títulos de alguns dos livros ou artigos que publicaram.

O primeiro capítulo - "Aspectos da evolução da Cartografia portuguesa (séculos XV a XIX)" - é assinado por Maria Fernanda Alegria e João Carlos Garcia (p. 27-84). Antes de se chegar à indicação das cartas mais importantes do século XIX, que anunciam a Cartografia portuguesa actual, os Autores apresentam aquelas que consideram "as obras fundamentais" e remontam às origens da nossa Cartografia - cartas portuguesas do século $\mathrm{XV}$, primeiras cartas com indicação das latitudes e mapas terrestres do século XVI são os pontos mais em destaque.

Ainda com carácter histórico, mas numa perspectiva completamente diferente, segue-se o segundocapítulo, "Difusão e ensino da Cartografia em Portugal", da autoria de Suzanne Daveau e Júlia Galego (p. 85123). O primeiro subcapítulo tem um título sugestivo - "De instrumento do poder à recente difusão pelo grande público"; aí se remonta de novo ao século XVI e ao século XVIII, antes de se falar da "difusão limitada dos mapas modernos". O segundo subcapítulo, "A Cartografia no ensino", recorre um pouco ao passado, mas debruça-se mais amplamente sobre as características dos mapas que marcaram a formação da maioria dos estudantes portugueses do nosso tempo.

José M. Barreiro Guedes, João M. Cordeiro Fernandes e Eduardo Saavedra, engenheiros geógrafos do Instituto Geográfico e Cadastral, assinam o terceiro capítulo - "Novos rumos para a Cartografia portuguesa" (p. 125-157). O recurso à história da Cartografia portuguesa é, agora, apenas um apontamento, do mesmo modo que a apresentação dos mapas actuais; o essencial do terceiro capítulo é a explicação de como se adquire hoje a informação cartográfica (levantamento de campo e detecção remota), como se armazena essa informação e como se caracterizam os Sistemas de Informação Geográfica (SIG).

"A Cartografia portuguesa moderna: os mapas temáticos" é o título do quarto capítulo, da responsabilidade de Suzanne Daveau (p. 159-181). Também aqui se nota um forte carácter histórico, com a apresentação de mapas temáticos dos séculos XIX e $\mathrm{XX}$, tal como dos que ilustraram algumas das teses de doutoramento em Geografia.

O quinto capítulo é dedicado a um tipo de mapas temáticos que nos interessa particularmente - "A Cartografia geomorfológica em Portugal"; assinam António de Brum Ferreira, Maria Luisa Rodrigues e José Luís Zêzere. Para além de vários mapas que se transformaram em verdadeiros clássicos para a Geomorfologia de Portugal (o "mapa morfostrutural de Portugal", de Orlando Ribeiro, o mapa da "glaciação da Serra da Estrela", de Suzanne Daveau, o "esboço morfológico do Baixo Alentejo e Algarve", de Mariano Feio e o "mapa geomorfológico de Portugal", de Denise de Brum Ferreira - figuras 31, 32, 33 e 34, respectivamente), os Autores referem muitos outros salientando, por exemplo, um dos vários esboços morfostruturais de Lúcio Cunha ("A Serra do Rabaçal e as serras setentrionais" do Maciço de Condeixa-Sicó-Alvaiázere, que estudou na sua tese de doutoramento em Geografia Física(1) - figura 36), bem como alguns mapas da escola de Lisboa, inclusivamente, um de riscos naturais ("O vale da ribeira de Fanhões" de J. L. Zêzere - figura 40).

O sexto capítulo, intitulado "Aspectos da produção e utilização actual dos mapas temáticos em Portugal" é da autoria de Maria Helena Dias. Trata-se de uma análise crítica bastante aprofundada das características dos diversos mapas temáticos existentes no nosso país, da sua concepção e do seu suporte espacial, com particular incidência na cartografia temática utilizada pela comunicação social.

Os dois últimos capítulos, sétimo e oitavo, vieram de especialistas francesas, ambas professoras na

(1) Ver: F. REBELO, “As Teses de Doutoramento em Geografia Física de Portugal (1949-1993)". Territorium, 1, 1994, p. 63-66. 
Universidade Louis Pasteur, de Strasbourg, e foram traduzidos por Maria Helena Dias - "Transformações cartográficas espaciais e anamorfoses", de Colette Cauvin (p. 267-310), e "A Cartografia e o computador", de Sylvie Rimbert (p. 311-344). Saliente-se que Colette Cauvin escolheu exclusivamente exemplos portugueses para ilustrar o seu texto, o que lhe dá, sem dúvida, uma maior força perante o leitor a que se destina (figuras 52 a 64), e que Sylvie Rimbert, tratando, uma vez mais, dos SIG, mostra claramente como, apesar da difusão de programas cartográficos para computadores, nem tudo está resolvido e ainda é possível fazer investigação em Cartografia distinguindo-se, assim, "novos amadores e novos cartógrafos" (p.337-339).

Dizer que todo este livro é muito importante para a geografia física aplicada ao ordenamento do território será um erro. No entanto, ele é de grande importância para todos os que estão interessados no ordenamento do território, não só pelos numerosos exemplos que apresenta, desde a cartografia de base à mais avançada cartografia temática, mas também pela descida ao pormenor na fundamentação, caracterização e perspectivas para ofuturoda cartografia geomorfológica e de riscos naturais, bem como dos Sistemas de Informação Geográfica (SIG).

\section{Fifth European Intensive Course on Applied Geomorphology ou o ponto da situação dos estudos sobre riscos naturais no sul de Portugal}

\section{Fernando Rebelo}

Com a participação de 45 geomorfólogos, oriundos das Universidades de Amsterdam, Bonn, Ferrara, Lisboa, Modena, Santander, Strasbourg, Utrecht, Wien e Zaragoza, e sob o patrocínio do Programa ERAMUS, realizou-se em Lisboa e no Algarve, entre 17 e 24 de Junho de 1996, um curso intensivo de Geomorfologia Aplicada.

A propósito deste curso e precisamente sob o título de Fifth European Intensive Course on Applied Geomorphology. Mediterranean and Urban Areas, foi editado, por António de Brum Ferreira e Gonçalo Teles Vieira, um conjunto de pequenos trabalhos que constituem um importante livro sobre riscos naturais no sul de Portugal (Lisboa, Faculdade de Letras da Universidade de Lisboa, 1996, 238 p.).

Após uma introdução assinada por M. Panizza e M. Soldati sobre os cursos intensivos ERASMUS, os três primeiros trabalhos referem-se jáà Geomorfologia de Portugal, mas são nitidamente de carácter introdutório - "Applied geomorphology in Mediterranean and urban areas: the example of Southern Portugal" (A. B. Ferreira), "Geomorphology of Portugal: long-term evolution and tectonic setting" (A. B. Ferreira) e "Geomorphology of Portugal: general aspects of the landforms" (D. B. Ferreira).

A primeira abordagem dos riscos naturais aparece no trabalho de A. B. Ferreira e J. L. Zêzere intitulado "Geodynamic hazards in Portugal" (p. 35-43). Salientam-se os riscos sísmicos, os movimentos de massa, as inundações e a erosão costeira. Segue-se um trabalho de Teresa Barata Salgueiro ("The urban development of Lisbon") que corresponde a uma apresentação da morfologia e da estrutura funcional da grande cidade que depois virá a ser estudada com pormenor no respeitante aos riscos naturais - "Notes for the characterization of the seismic vulnerability of building construction in Lisbon" (C. S. Oliveira), "Earthquake emergency planning and response. Application to the city of Lisbon" (I. Pais) e "Earthquakes in Lisbon's urban history. A theme for a guided visit" (I. Pais).

"Landslides in the north of Lisbon region" (p. 7989) é uma pequena síntese de José Luís Zêzere feita com base nas pesquisas que aí vem efectuando desde os anos 80 e que lhe permitiram recensear 597 casos de movimentos de massa, distribuidos por 5 tipos ("Shallow translational slides", "Translational slides", "Rotational slides", "Slides/falls due to lateral sapping", e "Complex movements") apenas em 5 áreas-amostra (Calhandriz, Fanhões, Trancão, Lousa e Loures).

Do mesmo Autor, seguem-se quatro pequenas notas de pormenor sobre outros tantos casos - "The Quinta da Boavista landslide. An example of mass movement in an ill-consolidated fill" (p. 91-93), "Mass movements in Fanhões area" (p. 95-99), "Mass movements and geomorphological hazard assessment in the Trancão valley, between Bucelas and Tojal" (p. 101-105) e "The multiple retrogressive slide of 